\title{
An investigation of cutting parameters effect on sound level, surface roughness, and power consumption during machining of hardened AISI 4140
}

\author{
Abidin Şahinoğlu ${ }^{1, *}$ and Efehan Ulas ${ }^{2,3}$ \\ ${ }^{1}$ Manisa Celal Bayar University, Vocational School of Manisa Technical Sciences, Machinary and Metal Technology \\ Department, Manisa, Turkey \\ ${ }^{2}$ Cankiri Karatekin University, Faculty of Science, Department of Statistics, 18200 Cankiri, Turkey \\ ${ }^{3}$ Simon Fraser University, Department of Statistics and Actuarial Science, Burnaby, BC, V5A 1S6, Canada
}

Received: 22 May 2020 / Accepted: 1 August 2020

\begin{abstract}
In recent years, the necessity for energy in the manufacturing industry has become an important problem because fossil fuel reserves are decreasing in order to produce energy. Therefore, the efficient use of energy has become an important research topic. In this study, energy efficiency is investigated in detail for sustainable life and manufacturing. AISI 4140 material with high hardness of 50 HRC hardness has been applied cryogenic process to improve mechanical and machinability properties. In this experiment study, the effects of feed rate $(0.04,0.08,0.12 \mathrm{~mm} / \mathrm{rev})$, cutting speed $(140,160,180 \mathrm{~m} / \mathrm{min})$, depth of cut $(0.05,0.10,0.15 \mathrm{~mm})$ and tool radius $(0.4,0.8)$ on energy consumption, surface roughness and sound intensity were investigated. Then, a new mathematical model with high accuracy was developed. Total power consumption was calculated by considering the instantaneous current value and machining time. As a result, it is found that good surface quality obtained when the feed rate is low, and the tool radius is high and the machining time is shortened, the energy consumption is reduced due to the increase in cutting speed, depth of cut and feed rate. Also, it is found that the tool radius has a limited effect on energy consumption, but low feed value increases energy consumption.
\end{abstract}

Keywords: Hard turning / AISI 4140 / sound level / power consumption / surface roughness / ANOVA

\section{Introduction}

Developments in machine technology have made widespread use of machine parts that are longer-lasting, lighter and more resistant to friction. In this study, AISI 4140 (DIN 1.7225 or $42 \mathrm{CrMo} 4$ ) material, which is suitable for heat treatment, is used. This material is widely used in the machine manufacturing industry, especially in the crankshaft, axle shaft, gear wheel, bolt, and nut construction. Increasing the strength of the material by heat treatment provides usability advantages for the material [1]. In addition, the workability and mechanic properties of these materials are improved by the cryogenic process. For these reasons, it is an important research topic to examine the workability properties of the material with cryogenic cooling. However, it has a wide range of applications and many works have been done on this topic.

The surface roughness is critical when the machine parts are contacted with each other. As the load carries

\footnotetext{
* e-mail: abidinsahinoglu@gmail.com
}

increases, the friction force increases. Therefore, the temperature is also increased. Increased temperature causes expansion and prevents machine parts from operating as desired. It causes more friction with an increasing amount of expansion. When the required cooling process is not carried out, this expansion and excessive friction prevent the machine parts from performing their work. Most of the time, it will cause the machine to become unavailable.

In some cases, the increased temperature causes the chemical structure to change in the machine parts and the mechanical properties of the material change. Therefore, the friction force not only increases the energy loss but also causes the machine to shorten or end its life. Both the low energy loss and the longer life of the machine make an essential contribution to ecological equilibrium. It reduces the need for energy for the use of less raw materials and the processing of the raw material. The surface roughness has a decisive effect on obtaining a long-lasting and highquality machine for the user and manufacturing company. Thus, many studies have been carried out on this subject [2-5]. In this study, the research has been carried out to obtain 
Table 1. The chemical composition of AISI 4140 material.

\begin{tabular}{lllllll}
\hline $\mathrm{C}$ & $\mathrm{Si}$ & $\mathrm{Mn}$ & Pmax & Smax & Cr & Mo \\
\hline $0.38-0.45$ & $0.15-0.40$ & $0.50-0.80$ & 0.035 & 0.035 & $0.90-1.20$ & $0.15-0.30$ \\
\hline
\end{tabular}

high surface quality, especially in hard turning. It is aimed to get a surface with grinding quality by the heat treatment applied to the material and the cryogenic process behind it.

While the most decisive cutting parameter on the surface quality is the feed rate, the tool geometry can produce better surface quality with a large radius. Therefore, the effects of the tool radius with the cutting parameters were investigated in this study. Since hard turning is a finish turning, surface quality has a significant parameter. Thus, the main goal of this study is to obtain excellent surface quality.

Another important parameter is energy consumption for ecological balance and productivity. The primary reason for energy consumption is the harmful gases emitted to the environment by fossil fuels [6]. Fossil fuel consumption leads to damage to the ozone layer, causes the harmful rays to reach the earth's surface, creates a greenhouse effect and global warming. This greenhouse effect causes the temperature to increase, and thus the glaciers melt. This change in temperature balance causes hurricanes to occur. Besides, the change in climate balance and an increase in agricultural land to be inundated causes significant damage to grain production, which will probably lead to hunger problems in the future. Energy efficiency used in the manufacturing industry is useful in solving all these problems because $60 \%$ of the energy is used in the manufacturing industry. The fact that most of the energy used in the manufacturing industry is obtained in fossil fuels makes it a significant problem in energy consumption [7-11]. In addition, due to the increasing energy prices, the decrease in energy resources and global production problems, it is of great importance to study energy efficiency. Determining the optimum cutting parameters for minimum energy consumption is one of the most important issues in the industry [10-13]. Therefore, many studies have been conducted on energy consumption [14-16]. The increase in the number of parts in the machine allows a reduction in costs, an increase in production speed, more environmentally friendly production and a higher chance of competition. The decrease in the workshop area leads to a reduction in investment costs, costs associated with lighting, cooling and heating. Multi-optimization has been performed in this study to reduce energy consumption and processing time without reducing workpiece quality $[17,18]$. The low feed rate improves surface quality during machining, however the machining time increases and hence energy consumption increases.

In this study, optimum cutting parameters were determined by multiple optimizations. Thus, the best surface quality is achieved in the shortest time and with minimum energy consumption. This study aims to minimize the surface roughness and power consumption during hard turning of AISI 4140 using CBN tools under dry cutting conditions. Three different cutting speeds, feed rates and depth of cuts and two nose radius were used in this work. Response surface method and ANOVA were employed to obtain the most significant parameters that affect responses.

\section{Material and methods}

\subsection{Material and chemical properties, mechanical properties}

In this experimental study, AISI 4140 material was kept at $950^{\circ} \mathrm{C}$ for $2 \mathrm{~h}$, and then oil was used to cool the material. Thus, heat treatment is applied, and then the material was stored at $340{ }^{\circ} \mathrm{C}$ for $1.5 \mathrm{~h}$ to reduce the stress on the material. Then it was expected to cool in the air. After $2 \mathrm{~h}$ at $-200{ }^{\circ} \mathrm{C}$ for $12 \mathrm{~h}$, the material was subjected to cytogenetical treatment. The heat treatment and cryogenic cooling process were measured at $50 \mathrm{HRC}$. With this process, the strength of the material is increased by 2.5 times. Then, nine channels were made with a distance of $20 \mathrm{~mm}$. A $1 \mathrm{~mm}$ diameter was turned to remove the hard layer on the workpiece surface. Table 1 gives the chemical composition of AISI 4140 material.

\subsection{Determining the cutting tool, tool holder and cutting parameters}

The materials with hardness values of $45 \mathrm{HRC}$ are particularly preferred due to their high-temperature resistance and low friction coefficient. Because of the low number of corners and the high cost of these tools, in this experimental study, the teams of Taegutec, which is produced for hard turning, is used due to the use of its four corners and economic reason. In addition, tools with a radius of 0.4 and $0.8 \mathrm{~mm}$ were used to see the effects of the tool radius, which had a significant effect on surface roughness [19]. The coolant has been used to prevent high temperatures from hardening and machining of the hardened 4140 steel from the $50 \mathrm{HRC}$ hardness [20]. Generally, although the use of coolant in the CBN and Ceramic tools is not required, however, in some studies, coolant is used to prevent the high temperature formed at the carbide inserts to damage both the workpiece and the tool.

The primary cutting-edge angle of $95^{\circ}$ and $-6^{\circ}$ cleaner angle is used for DCMT 120404-08. The tool holder is as short as possible as the height of the tool increases the vibration.

When determining the cutting parameters, the tool catalog values are considered. The cutting speed is selected to be high, while the cutting depth is selected as low as it will be done for a finish turning. Increasing the hardness of the material increases the breaking strength. Therefore, low feed and low depth of cut are preferred. The average 


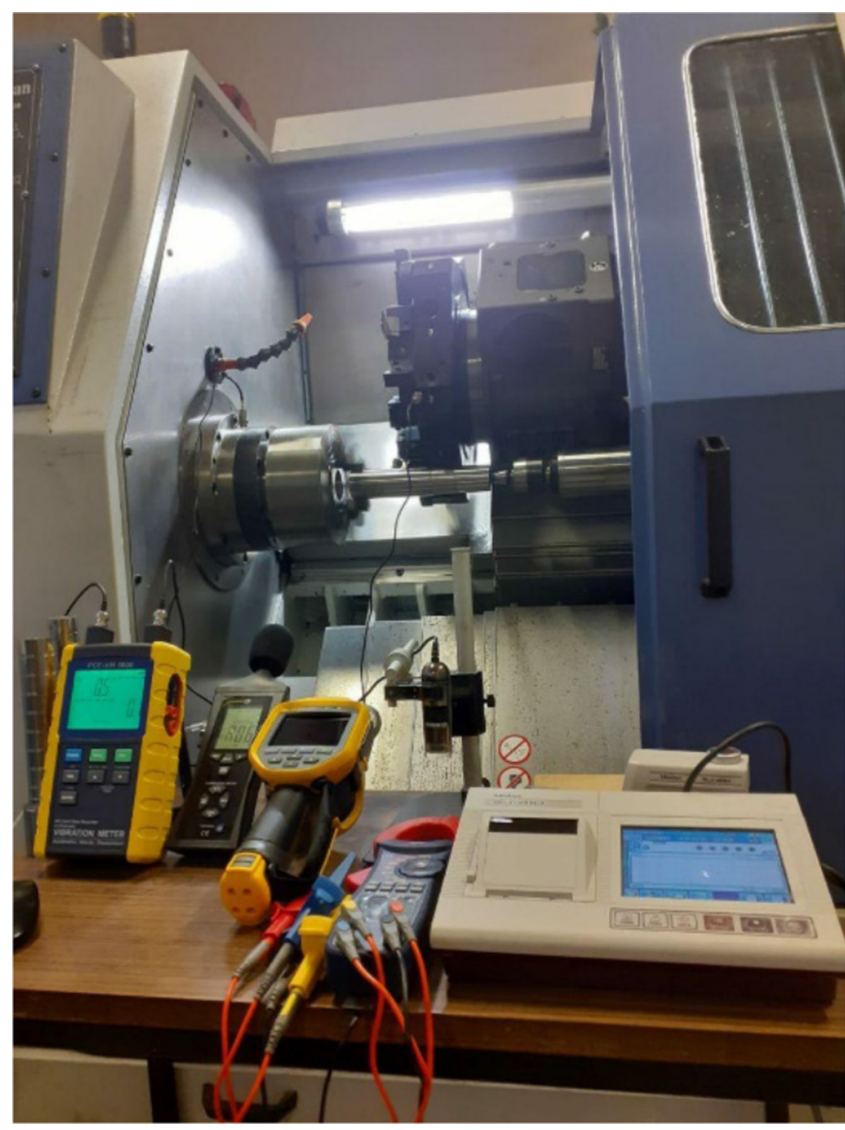

Fig. 1. Experimental setup.

values for the surface roughness value have been determined because the feed rate should not exceed $1 / 4$ of the tool radius for the excellent surface quality.

\subsection{CNC machine and machining conditions}

TTC 630 CNC turning machine of TAKSAN was used in the experimental study. The rigidity of the machine tool affects the machining conditions positively, depending on the vibrations. The workpiece is connected between the chuck and center point under dry cutting conditions. Since the material length is more than three times the material diameter, the material is connected between the chuck and center point. In this way, the vibration on the workpiece is minimized. The experimental setup is shown in Figure 1.

\subsection{Measurement process}

During the processing experiments, data were obtained for each experiment. The current value and sound intensity were measured instantly. The current through a phase was measured with the UNI-T UT201 digital clamp multimeter. This value is multiplied by 3 to obtain the total current value. The regulator to which the machine tools are connected has kept the voltage fluctuation to a minimum at $230 \mathrm{~V}$. The machining process was calculated to remove an equal amount of chips in each material. Total power consumption is calculated by multiplying current, voltage and processing time.
Table 2. Parameters with their values at two-three levels.

\begin{tabular}{llccc}
\hline Factors & Parameters & Level 1 & Level 2 & Level 3 \\
\hline Radius & Nose Radius $(\mathrm{mm})$ & 0.4 & 0.8 & \\
A & Depth of cut $(\mathrm{mm})$ & 0.05 & 0.1 & 0.15 \\
F & Feed rate $(\mathrm{mm} / \mathrm{rev})$ & 0.04 & 0.08 & 0.12 \\
V & Cutting speed & 140 & 160 & 180 \\
& $(\mathrm{~m} / \mathrm{min})$ & & & \\
\hline
\end{tabular}

The sound intensity was measured with the Lutron SL-401 sound intensity meter at a distance of $600 \mathrm{~mm}$ from the workpiece. The device measured the volume in slow position and Filter A. The average sound intensity was calculated so that instant chip sounds do not affect the measurement. Instant measurements were recorded with the camera. The sound intensity and current values were started to be taken 4 seconds after the workpiece started to be processed.

Immediately after each test, the surface roughness value was measured with the Mitutoyo SJ 201 roughness tester. Before measurements, the accuracy of the instrument was verified by the calibration block. The sampling range of the instrument is $0.8 \mathrm{~mm}$. The device is parallel to the measured surface. Three surface roughness values were measured for each experiment, and then the arithmetic mean was taken.

\subsection{Linear regression}

Suppose we want to see how response variable $y$ relates to explanatory variables $x_{1}, \ldots, x_{p}$. Thus, we have equation (1):

$$
x_{i 1}, \ldots, x_{i p}, y_{i}, i=1, \ldots, n
$$

The response of the linear predictor is a linear combination of model involving the explanatory variables, and the error term is the variation in the response for identical values of the explanatory variables. In order to explain the response depends on the explanatory variables, the statistical model can be written as equation (2):

$$
y_{i}=\beta_{0}+\beta_{1} x_{i 1}+\cdots+\beta_{p} x_{i p}+\varepsilon_{i}
$$

Here $\varepsilon_{i}$ is the error term and $\beta_{0}+\beta_{1} x_{i 1}+\cdots+\beta_{p} x_{i p}$ are the linear predictor. Alternatively, the relationship between $y$ and $x$ can be expressed in a quadratic way as equation (3):

$$
y_{i}=\beta_{0}+\beta_{1} x_{i}+\beta_{2} x_{i}^{2}+\varepsilon_{i}
$$

It is important that in order to apply the theory underpinning linear models, the error term must be normally distributed. Analysis of variance is performed in order to quantify the influence of selected parameters and interactions in 4140-2 composites. Table 2 shows the parameters with their values at two-three levels. The experimental analyses were performed using Minitab software. Pooled version of ANOVA for power consumption, 
Table 3. ANOVA for power consumption.

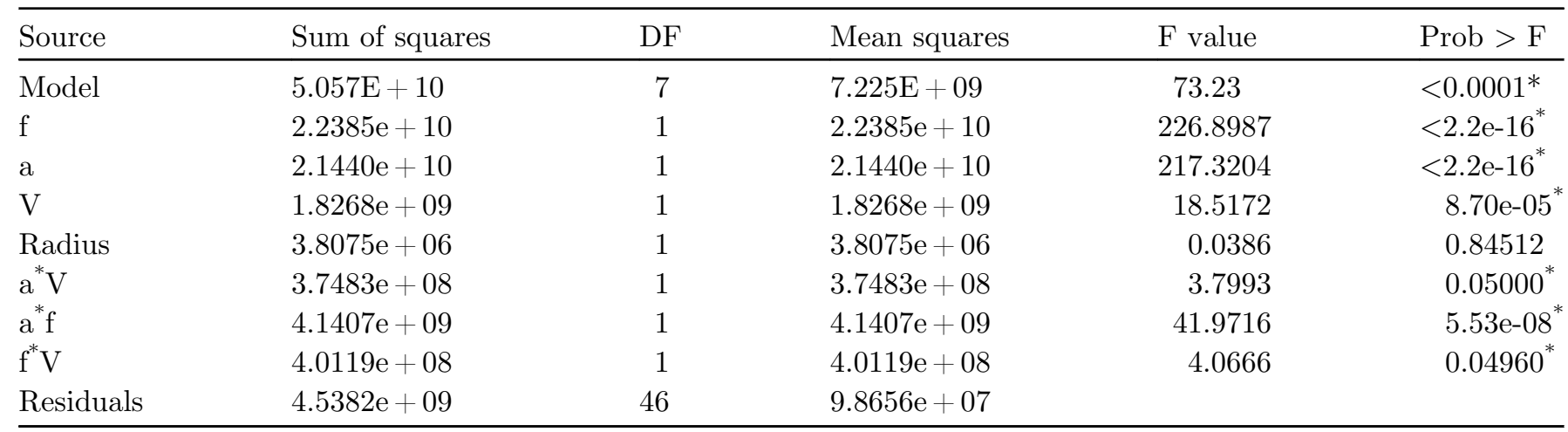

*Significant at $95 \%$ confidence interval, Predicted $R^{2}: 0.92, \mathrm{Adj} . R^{2}: 0.91$.

Table 4. ANOVA for sound level.

\begin{tabular}{lcccc}
\hline Source & Sum of squares & DF & Mean squares & F value \\
\hline Model & 164.47 & 5 & 32.89 & 36.88 \\
f & 0.467 & 1 & 0.467 & 0.5235 \\
a & 61.623 & 1 & 61.623 & 69.0814 \\
V & 0.934 & 1 & 0.934 & 0.4729 \\
Radius & 52.215 & 1 & 52.215 & $7.479 \mathrm{e}-1^{*}$ \\
a Radius & 49.234 & 1 & 49.234 & 58.5352 \\
Residuals & 42.817 & 48 & 0.892 & 55.1929 \\
\hline
\end{tabular}

*Significant at $95 \%$ confidence interval, Predicted $R^{2}: 0.82, \mathrm{Adj} . R^{2}: 0.81$.

Table 5. ANOVA for surface roughness.

\begin{tabular}{llclrc}
\hline Source & Sum of Squares & DF & Mean squares & F value & Prob $>$ F \\
\hline Model & 3.03 & 5 & 0.6052 & 62.91 & $<0.0001^{*}$ \\
$\mathrm{f}$ & 1.17361 & 1 & 1.17361 & 122.1785 & $8.625 \mathrm{e}-1^{*}$ \\
a & 0.02778 & 1 & 0.02778 & 2.8918 & 0.0955 \\
V & 0.01138 & 1 & 0.01138 & 1.1845 & 0.2819 \\
Radius & 1.33796 & 1 & 1.33796 & 139.2883 & $8.510 \mathrm{e}-1^{*}$ \\
f Radius $^{*}$ Residuals & 0.47610 & 1 & 0.47610 & 49.5643 & $6.381 \mathrm{e}-1^{*}$ \\
\hline
\end{tabular}

${ }^{*}$ Significant at $95 \%$ confidence interval, Predicted $R^{2}: 0.85, \operatorname{Adj} . R^{2}: 0.86$.

sound level and surface roughness of 4140-2 composites are given in Tables $3-5$, respectively.

\section{Results and discussion}

The experimentally measured values of motor current, power consumption, time, sound level and surface roughness are shown in Table 6.

Tests for significance on individual parameters need to be performed to select the significant parameters in the model. Table 4 shows the results of ANOVA for each parameter. Values of Prob $>\mathrm{F}$ less than 0.05 indicate model terms are significant. Some of the model terms were found to be significant. So that $\mathrm{f}, \mathrm{a}, \mathrm{V}, \mathrm{a}^{*} \mathrm{~V}, \mathrm{a}^{*} \mathrm{f}$ and $\mathrm{f}^{*} \mathrm{~V}$ are significant model terms for power consumption. On the other hand, the radius is an insignificant model term. This term can be removed from the final model. Otherwise, this model term will affect our model negatively. It may reduce the $R^{2}$ probability. The final model for power consumption is found by backward model selection. All model terms except radius are found to be significant in the final model. However, the depth of cut and feed rate were found to be the most significant parameters in the final model. In addition, the predicted $R^{2}$ value is high and very similar to the adjusted $R^{2}$. The following equation is the final empirical model for power consumption. In addition, 3D graphs of power consumption and Mean changes in selected 
Table 6. Experimental results.

\begin{tabular}{|c|c|c|c|c|c|c|c|c|c|}
\hline $\begin{array}{l}\text { Sample } \\
\text { No }\end{array}$ & $\begin{array}{l}\text { Nose } \\
\text { Radius } \\
(\mathrm{mm})\end{array}$ & $\mathrm{a}(\mathrm{mm})$ & $\mathrm{V}(\mathrm{m} / \mathrm{min})$ & $\mathrm{f}(\mathrm{mm} / \mathrm{rev})$ & $\begin{array}{l}\text { Current } \\
\text { (A) }\end{array}$ & $\begin{array}{l}\text { Power } \\
\text { consumption } \\
\text { (Watt) }\end{array}$ & $\begin{array}{l}\text { Time } \\
(\mathrm{s})\end{array}$ & $\begin{array}{l}\text { Sound } \\
\text { level } \\
(\mathrm{dB}) \\
\end{array}$ & $\begin{array}{l}\text { Surface } \\
\text { roughness } \\
(\mu \mathrm{m})\end{array}$ \\
\hline 1 & 0.4 & 0.05 & 140 & 0.04 & 2.57 & 141753.9 & 83.57 & 74.7 & 0.26 \\
\hline 2 & 0.4 & 0.05 & 140 & 0.08 & 2.67 & 73634.79 & 41.79 & 74.3 & 0.45 \\
\hline 3 & 0.4 & 0.05 & 140 & 0.12 & 2.6 & 47802.86 & 27.86 & 74.2 & 0.85 \\
\hline 4 & 0.4 & 0.05 & 160 & 0.04 & 2.43 & 117277.9 & 73.13 & 74 & 0.26 \\
\hline 5 & 0.4 & 0.05 & 160 & 0.08 & 2.47 & 59604.19 & 36.56 & 74.2 & 0.45 \\
\hline 6 & 0.4 & 0.05 & 160 & 0.12 & 2.51 & 40379.63 & 24.38 & 74.3 & 0.77 \\
\hline 7 & 0.4 & 0.05 & 180 & 0.04 & 2.43 & 104247 & 65.00 & 73.8 & 0.61 \\
\hline 8 & 0.4 & 0.05 & 180 & 0.08 & 2.46 & 52767 & 32.50 & 73.7 & 0.46 \\
\hline 9 & 0.4 & 0.05 & 180 & 0.12 & 2.56 & 36608 & 21.67 & 73.8 & 0.61 \\
\hline 10 & 0.4 & 0.1 & 140 & 0.04 & 2.66 & 73359 & 41.79 & 74.7 & 0.34 \\
\hline 11 & 0.4 & 0.1 & 140 & 0.08 & 2.74 & 37782.64 & 20.89 & 74.8 & 0.5 \\
\hline 12 & 0.4 & 0.1 & 140 & 0.12 & 2.78 & 25556.14 & 13.93 & 74.9 & 1.01 \\
\hline 13 & 0.4 & 0.1 & 160 & 0.04 & 2.54 & 61293.38 & 36.56 & 74.4 & 0.28 \\
\hline 14 & 0.4 & 0.1 & 160 & 0.08 & 2.59 & 31249.97 & 18.28 & 74.5 & 0.55 \\
\hline 15 & 0.4 & 0.1 & 160 & 0.12 & 2.66 & 21396.38 & 12.19 & 74 & 0.99 \\
\hline 16 & 0.4 & 0.1 & 180 & 0.04 & 2.54 & 54483 & 32.50 & 73.6 & 0.28 \\
\hline 17 & 0.4 & 0.1 & 180 & 0.08 & 2.61 & 27992.25 & 16.25 & 74.1 & 0.61 \\
\hline 18 & 0.4 & 0.1 & 180 & 0.12 & 2.71 & 19376.5 & 10.83 & 74.2 & 0.99 \\
\hline 19 & 0.4 & 0.15 & 140 & 0.04 & 2.73 & 50193 & 27.86 & 75.1 & 0.4 \\
\hline 20 & 0.4 & 0.15 & 140 & 0.08 & 2.79 & 25648.07 & 13.93 & 74.7 & 0.55 \\
\hline 21 & 0.4 & 0.15 & 140 & 0.12 & 2.84 & 17405.14 & 9.29 & 74.8 & 1.03 \\
\hline 22 & 0.4 & 0.15 & 160 & 0.04 & 2.61 & 41988.38 & 24.38 & 74.1 & 0.44 \\
\hline 23 & 0.4 & 0.15 & 160 & 0.08 & 2.72 & 21879 & 12.19 & 74.3 & 0.6 \\
\hline 24 & 0.4 & 0.15 & 160 & 0.12 & 2.77 & 14854.13 & 8.13 & 74.4 & 1.11 \\
\hline 25 & 0.4 & 0.15 & 180 & 0.04 & 2.66 & 38038 & 21.67 & 73.8 & 0.23 \\
\hline 26 & 0.4 & 0.15 & 180 & 0.08 & 2.75 & 19662.5 & 10.83 & 74.1 & 0.55 \\
\hline 27 & 0.4 & 0.15 & 180 & 0.12 & 2.84 & 13537.33 & 7.22 & 74.2 & 1.06 \\
\hline 28 & 0.8 & 0.05 & 140 & 0.04 & 2.64 & 145614.9 & 83.57 & 68.1 & 0.3 \\
\hline 29 & 0.8 & 0.05 & 140 & 0.08 & 2.66 & 73359 & 41.79 & 68.4 & 0.28 \\
\hline 30 & 0.8 & 0.05 & 140 & 0.12 & 2.69 & 49457.57 & 27.86 & 68.6 & 0.43 \\
\hline 31 & 0.8 & 0.05 & 160 & 0.04 & 2.5 & 120656.3 & 73.13 & 68.7 & 0.27 \\
\hline 32 & 0.8 & 0.05 & 160 & 0.08 & 2.52 & 60810.75 & 36.56 & 69.1 & 0.32 \\
\hline 33 & 0.8 & 0.05 & 160 & 0.12 & 2.55 & 41023.13 & 24.38 & 69.4 & 0.4 \\
\hline 34 & 0.8 & 0.05 & 180 & 0.04 & 2.48 & 106392 & 65.00 & 69.5 & 0.17 \\
\hline 35 & 0.8 & 0.05 & 180 & 0.08 & 2.5 & 53625 & 32.50 & 69.6 & 0.27 \\
\hline 36 & 0.8 & 0.05 & 180 & 0.12 & 2.61 & 37323 & 21.67 & 69.9 & 0.36 \\
\hline 37 & 0.8 & 0.1 & 140 & 0.04 & 2.7 & 74462.14 & 41.79 & 74.1 & 0.28 \\
\hline 38 & 0.8 & 0.1 & 140 & 0.08 & 2.74 & 37782.64 & 20.89 & 74.4 & 0.23 \\
\hline 39 & 0.8 & 0.1 & 140 & 0.12 & 2.78 & 25556.14 & 13.93 & 74.8 & 0.42 \\
\hline 40 & 0.8 & 0.1 & 160 & 0.04 & 2.56 & 61776 & 36.56 & 73.4 & 0.2 \\
\hline 41 & 0.8 & 0.1 & 160 & 0.08 & 2.6 & 31370.63 & 18.28 & 73.5 & 0.25 \\
\hline 42 & 0.8 & 0.1 & 160 & 0.12 & 2.69 & 21637.69 & 12.19 & 73.6 & 0.3 \\
\hline 43 & 0.8 & 0.1 & 180 & 0.04 & 2.53 & 54268.5 & 32.50 & 73.7 & 0.17 \\
\hline 44 & 0.8 & 0.1 & 180 & 0.08 & 2.66 & 28528.5 & 16.25 & 73.8 & 0.21 \\
\hline 45 & 0.8 & 0.1 & 180 & 0.12 & 2.78 & 19877 & 10.83 & 74.1 & 0.33 \\
\hline 46 & 0.8 & 0.15 & 140 & 0.04 & 2.75 & 50560.71 & 27.86 & 74.3 & 0.31 \\
\hline 47 & 0.8 & 0.15 & 140 & 0.08 & 2.79 & 25648.07 & 13.93 & 74.5 & 0.27 \\
\hline
\end{tabular}


Table 6. (continued).

\begin{tabular}{lllllllrll}
\hline $\begin{array}{l}\text { Sample } \\
\text { No }\end{array}$ & $\begin{array}{l}\text { Nose } \\
\text { Radius } \\
(\mathrm{mm})\end{array}$ & $\mathrm{a}(\mathrm{mm})$ & $\mathrm{V}(\mathrm{m} / \mathrm{min})$ & $\mathrm{f}(\mathrm{mm} / \mathrm{rev})$ & $\begin{array}{l}\text { Current } \\
(\mathrm{A})\end{array}$ & $\begin{array}{l}\text { Power } \\
\text { consumption } \\
(\text { Watt })\end{array}$ & $\begin{array}{l}\text { Time } \\
(\mathrm{s})\end{array}$ & $\begin{array}{l}\text { Sound } \\
\text { level } \\
(\mathrm{dB})\end{array}$ & $\begin{array}{l}\text { Surface } \\
\text { roughness } \\
(\mu \mathrm{m})\end{array}$ \\
\hline 48 & 0.8 & 0.15 & 140 & 0.12 & 2.84 & 17405.14 & 9.29 & 74 & 0.37 \\
49 & 0.8 & 0.15 & 160 & 0.04 & 2.56 & 41184 & 24.38 & 73.6 & 0.25 \\
50 & 0.8 & 0.15 & 160 & 0.08 & 2.66 & 21396.38 & 12.19 & 73.7 & 0.28 \\
51 & 0.8 & 0.15 & 160 & 0.12 & 2.72 & 14586 & 8.13 & 74.1 & 0.34 \\
52 & 0.8 & 0.15 & 180 & 0.04 & 2.6 & 37180 & 21.67 & 73.7 & 0.17 \\
53 & 0.8 & 0.15 & 180 & 0.08 & 2.71 & 19376.5 & 10.83 & 73.9 & 0.21 \\
54 & 0.8 & 0.15 & 180 & 0.12 & 2.78 & 13251.33 & 7.22 & 74.1 & 0.35 \\
\hline
\end{tabular}

parameters on power consumption are shown in Figures 2 and 3, respectively. Regression equation (4) for power consumption is:

$$
\begin{gathered}
\text { Power Consumption }=383354.091-2097868.031 \\
\quad{ }^{*} \mathrm{f}-1645793.572^{*} \mathrm{a}-160.233^{*} \mathrm{~V}+3951.93 \\
{ }^{*} \mathrm{a}^{*} \mathrm{~V}+656755.18^{*} \mathrm{f}^{*} \mathrm{a}+5110.69^{*} \mathrm{f}^{*} \mathrm{~V}
\end{gathered}
$$

Cutting speed and feed rate have an essential effect on power consumption because these parameters reduce the machining time. Although these parameters increase the current value slightly, decrease machining time significantly. Therefore, it is necessary to increase the cutting parameters to achieve a lower processing time to obtain minimum power consumption. In this case, much more work can be done in a shorter time, and it results in decreasing the time of processing and consequently minimizing the power consumption. Also, nose radius has no critical effect on power consumption. The same results obtained in $[3,10,16]$ studies.

In machining, the current value is an important indicator of power consumption. While the current rating increases, power consumption is also increased. However, the most effective parameter in power consumption is processing time. As the cutting parameters increase, the current value increases, but the processing time is shortened. Even if the motor current value increases, the total power consumption decreases as the machining time decreases. Therefore, the processing time is a more important parameter in power consumption. Another reason why the machining time is useful in power consumption is that it consumes significant current as the machine tool is idle. (no load). 1.5 A of the average consumed current is consumed for the idle operation of the machine tool. High or low chip removal affects the total current value slightly. Therefore, it is crucial to keep the machining time as short as possible in terms of power consumption. This means that the machining time must be kept short by selecting the high cutting speed, depth of cut and feed rate. Keeping the machining time short will enable the machine to produce a large number of parts in a short time, so it reduces investment costs.

The least effective parameter for changing the instantaneous current value (power consumption) is the tool radius. The tool radius does not affect the current value significantly, while it affects the surface roughness importantly. Therefore, for low power consumption and good surface quality, tools with a large tool radius should be preferred.

The Model $F$-value of 36.88 implies the model is significant. There is only a $0.01 \%$ chance that an $F$-value this large could occur due to noise. $P$-values less than 0.05 indicate model terms are significant. In this case, Depth of Cut (a), Radius and Depth of Cut*Radius are significant model terms. Values higher than 0.05 indicate the model terms are not significant. If there are many insignificant model terms (not counting those required to support hierarchy), model reduction may improve our model. The same results are obtained in the $[5,10]$ studies. Besides, 3D graphs of sound level and Mean changes in selected parameters on the sound level are shown in Figures 4 and 5 , respectively. Regression equation (5) for the sound level is:

$$
\begin{aligned}
\text { Sound Level }= & 81.712962963-44^{*} \mathrm{a}-16.61110 \\
& { }^{*} \mathrm{R}+116.944^{*} \mathrm{a}{ }^{*} \mathrm{R}
\end{aligned}
$$

Since there is a low depth of cut in finishing, there is no significant change in sound volume. The increase in the depth of the chip creates a greater force, causing some increase in sound intensity. Although the cutting speed and feed rate affect the force on the tool, a low cutting force has caused the change in sound volume to be minimal. The sound intensity of $74 \mathrm{~dB}$ is not a problem in terms of operator health. A high volume of sound means that the machine tool is forced, but in these processing conditions, it is seen from the obtained sound intensity that the machine tool is not forced. In addition, 3D graphs of surface roughness and Mean changes in selected parameters on surface roughness are shown in Figures 6 and 7 , respectively.

Regression equation (6) for surface roughness is:

$$
\begin{aligned}
& \text { Surface Roughness }=-4.814815 \mathrm{e}-02+1.313889 \mathrm{e} \\
& +01^{*} \mathrm{f}+3.629630 \mathrm{e}-01^{*} \text { Radius }-1.437500 \mathrm{e} \\
& +01^{*} \text { Radius }{ }^{*} \mathrm{f}
\end{aligned}
$$

The Model $F$-value of 62.91 implies the model is significant. There is only a $0.01 \%$ chance that an $F$-value this large could occur due to noise. 

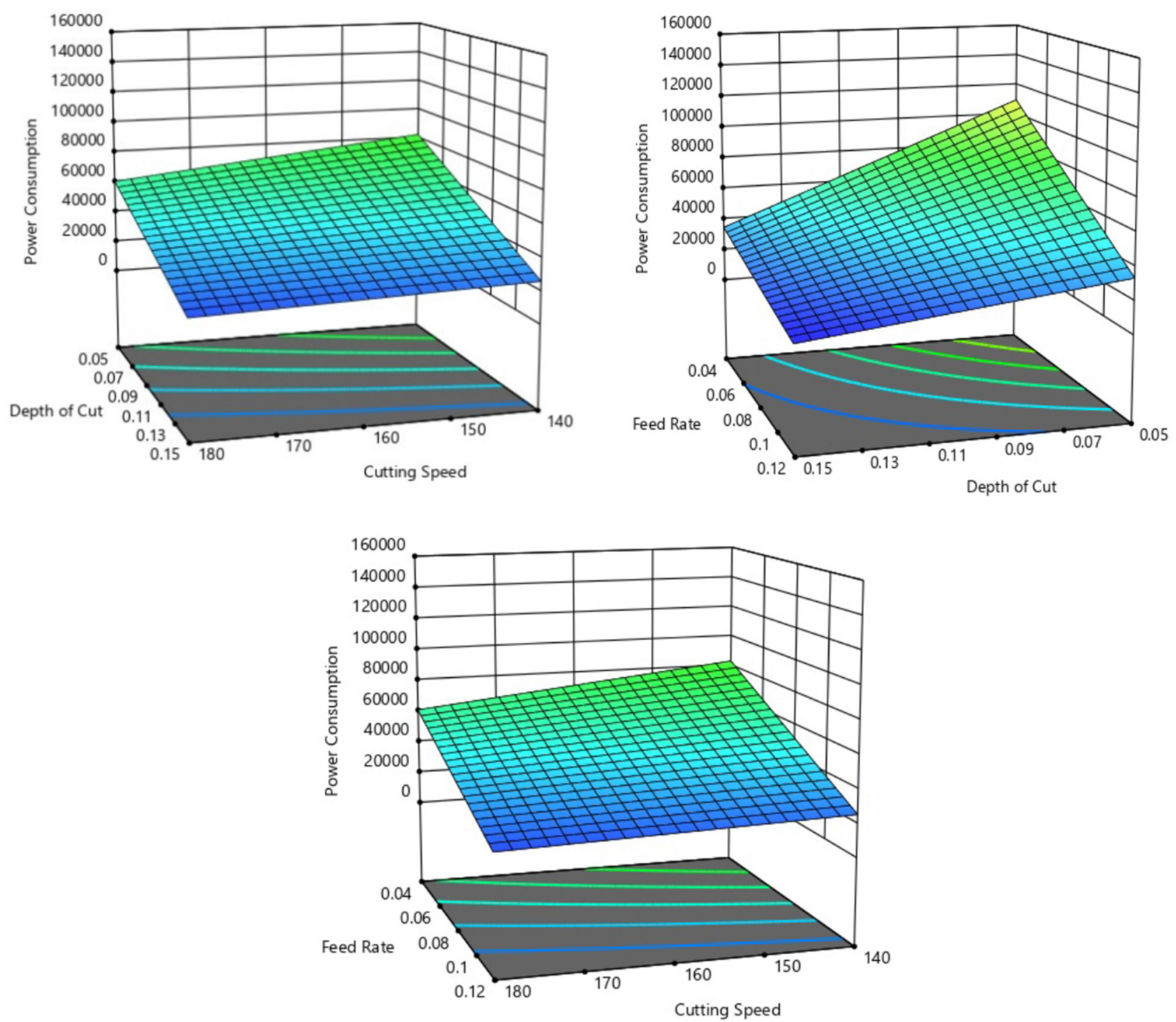

Fig. 2. 3D graphs of power consumption.
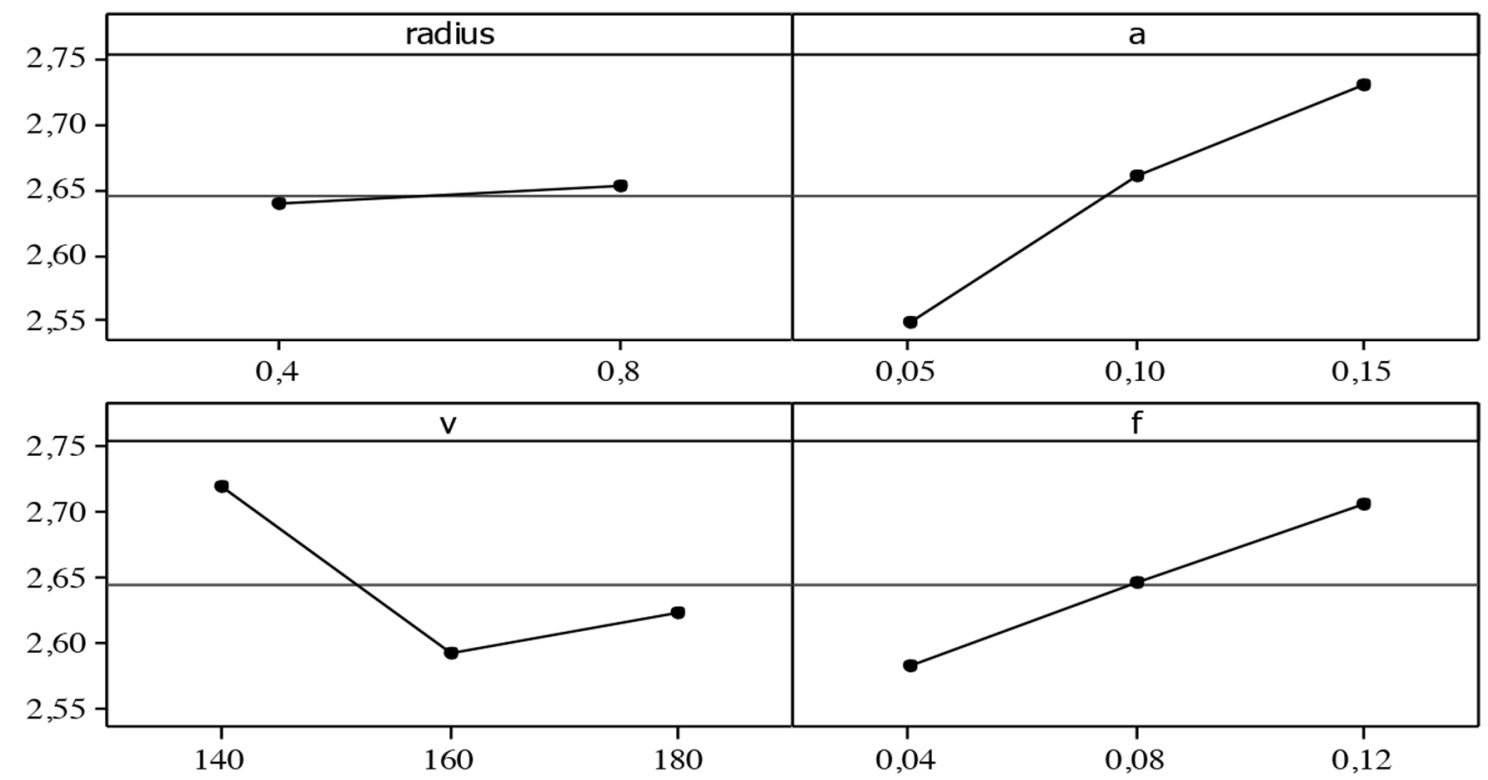

Fig. 3. Mean changes in selected parameters on power consumption. 
$P$-values less than 0.05 indicate model terms are significant. In this case, the Feed Rate (f), Radius and Feed Rate* Radius are significant model terms. Values higher than 0.05 indicate the model terms are not significant. If there are many insignificant model terms, model reduction may improve the model. The Predicted $\mathrm{R}^{2}$ of 0.85 is in reasonable agreement with the Adjusted $R^{2}$ of 0.86 ; the difference is less than 0.01 . Most of the studies $[3-5,13,20]$, indicate the significant effect of feed rate on the surface roughness.

One of the most important parameters in finish turning is low surface roughness. For low surface roughness values, the tool with large tool radius and low feed values should be preferred. It is seen that the depth of cut and the cutting speed have a low effect. Increasing the feed rate means increasing the depth of the helix groove on the workpiece.

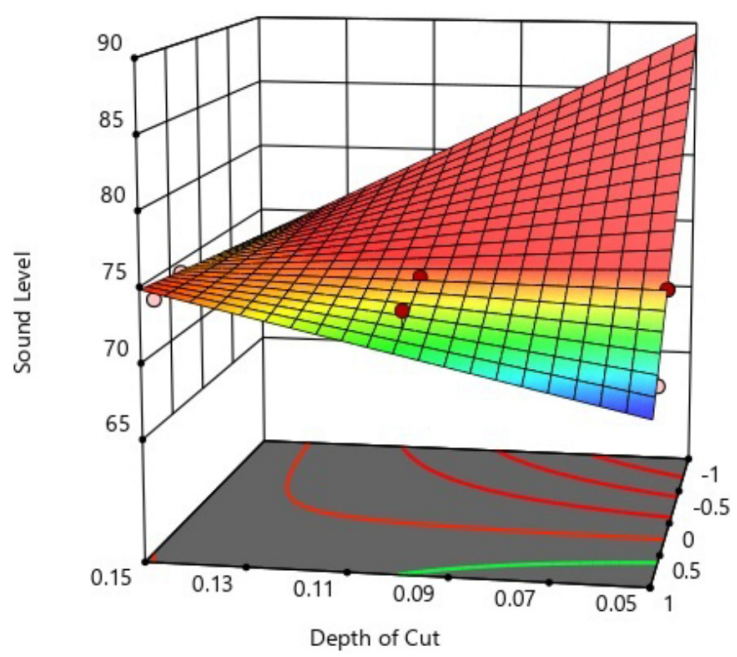

Radius

Fig. 4. 3D graphs of sound level.
In this case, the surface roughness value increases. The growth of the tool radius means that the cutting tool contacts the workpiece edge over a longer distance at a constant feed rate. In this case, the surface roughness value decreases. Feed rates up to $1 / 4$ of the tool radius can be preferred. In these processing conditions, the surface roughness values between 0.3 and 0.9 microns are of great importance as it provides a grinding quality surface.

The high cutting speed is important for manufacturing, as it allows more products to be obtained. The increase in cutting speed is an important parameter since it does not decrease the surface quality and ensures low energy consumption.

\subsection{The smaller, the better}

Since our goal is to minimize power consumption, sound level and surface roughness, the smaller, the better equation is applied to determine the individual desirability values for power consumption, sound level, and surface roughness. The equation (7) for the smaller, the better can be seen below.

$$
d i={ }_{0}^{1}\left(\frac{\bar{y}-y_{\max }}{y_{\min }-y_{\max }}\right)^{r}, y_{\min } \leq \bar{y} \leq y_{\max },\left\{\begin{array}{l}
\bar{y} \leq y_{\min } \\
r \geq 0 \\
\bar{y} \geq y_{\max }
\end{array}\right.
$$

We expect the value of $\bar{y}$ to be the smallest. If the value of $\bar{y}$ is less than a criteria value, the desirability value equal to 1 . Otherwise, the desirability value equals to 0 . In this equation, $y_{\min }$ and $y_{\max }$ represents the lower and upper tolerance limit of $\bar{y}$ respectively. Moreover, the value of $r$ shows the weight. The weight might be set to the smaller value if the corresponding response is not close to the target. In other cases, the weight can be set to the larger value.
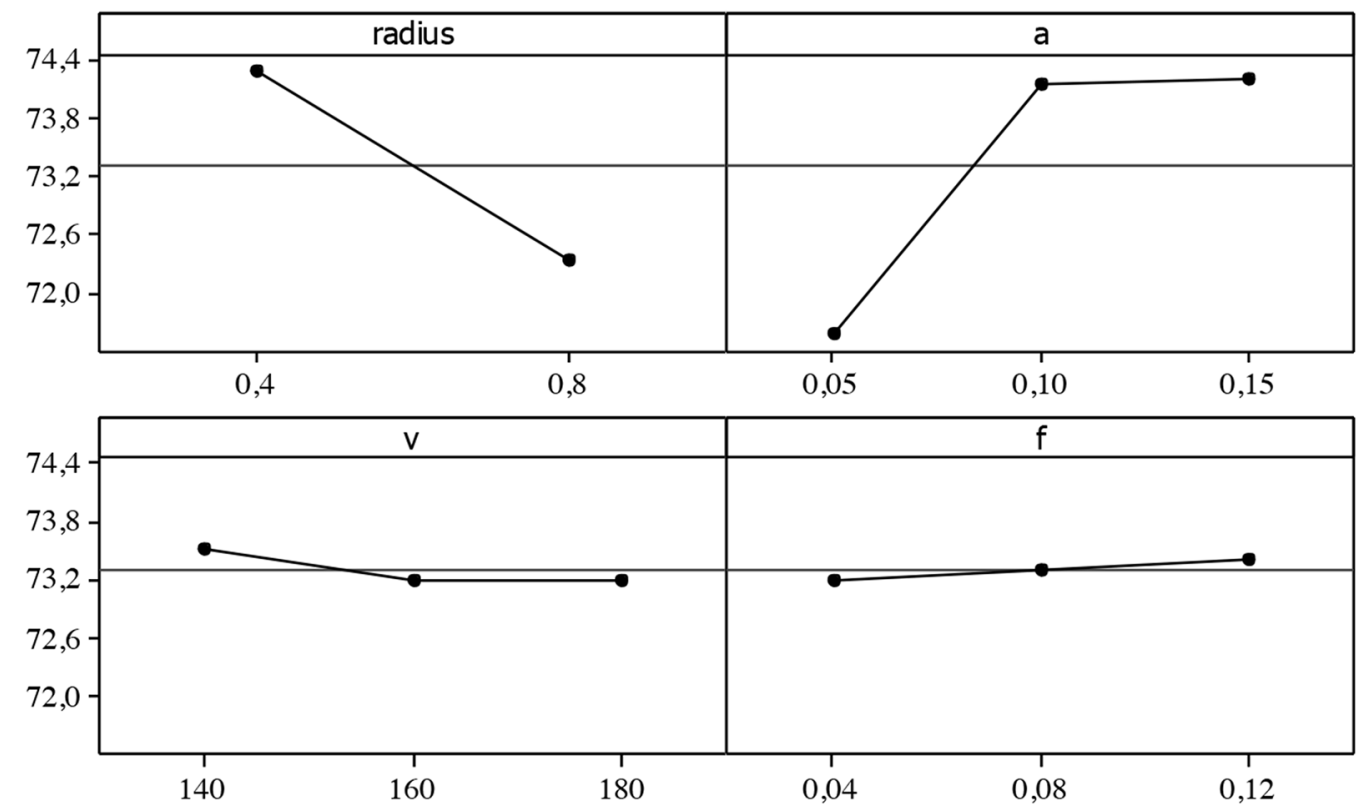

Fig. 5. Mean changes in selected parameters on the sound level. 
To minimize power consumption, sound level and surface roughness, the optimization of process parameters is an important procedure. Researchers have used many different optimization techniques. However, the multiresponse optimization analysis has been carried out to obtain the minimum power consumption, sound level and surface roughness in our analysis. In addition, the desirability function-based approach is used to optimize the process parameters. The normal plots of the minimum power consumption, sound level and surface roughness are shown in Figure 8.

The cutting parameters are optimal levels in chip removal. Cutting parameters also have optimum values according to the material being processed. Therefore, parameters can be changed within these limits. However,

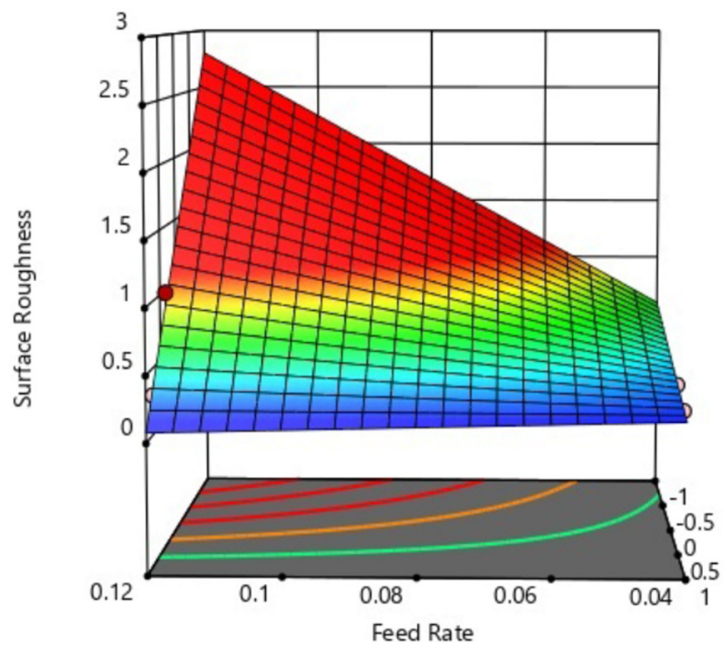

Fig. 6. 3D graphs of surface roughness. the rigidity of the machine, cutting tool properties, coolant or dry cutting conditions affects the machining conditions. This situation may vary between machines. The dimensions of the workpiece can make it difficult to determine the optimum values for the machining type. Identifying optimal processing conditions is a complex process. In this highly variable manufacturing process, the parameters that are important for hard turning are evaluated. As it is intended to give a general idea, possible causes of different situations that may be encountered are explained.

Very high surface roughness values should be avoided in hard turning, which is a finishing turning process. At the same time, high cutting speed, low feed rate and low depth of cut are preferred to shorten machining time and reduce energy consumption. These preferences may vary on nonrigid machine tools.

Due to the hardness of the workpiece material, a cutting tool suitable for a hardness of $45-50$ HRC is preferred. Failure to do so may result in tool breakage or very rapid wear $[21,22]$. The fact that there was no significant change in sound volume prevented the sound from being an important indicator of hard turning operations. The minimum value of power consumption, sound level and surface roughness is considered as better performance measures. Therefore, equation (7) is used to calculate the individual desirability values for power consumption, sound level and surface roughness.

Desirability analysis is carried out to minimize the power consumption, sound level and surface roughness. The main objective of Optimization is to reduce the cost of used tools. A multi-response optimization solution for minimum power consumption, sound level and surface roughness is given in Table 7 . The best solution has the highest desirability score. Solution number one has selected as the best. Desirability graphs of response variables are shown in Figure 9.

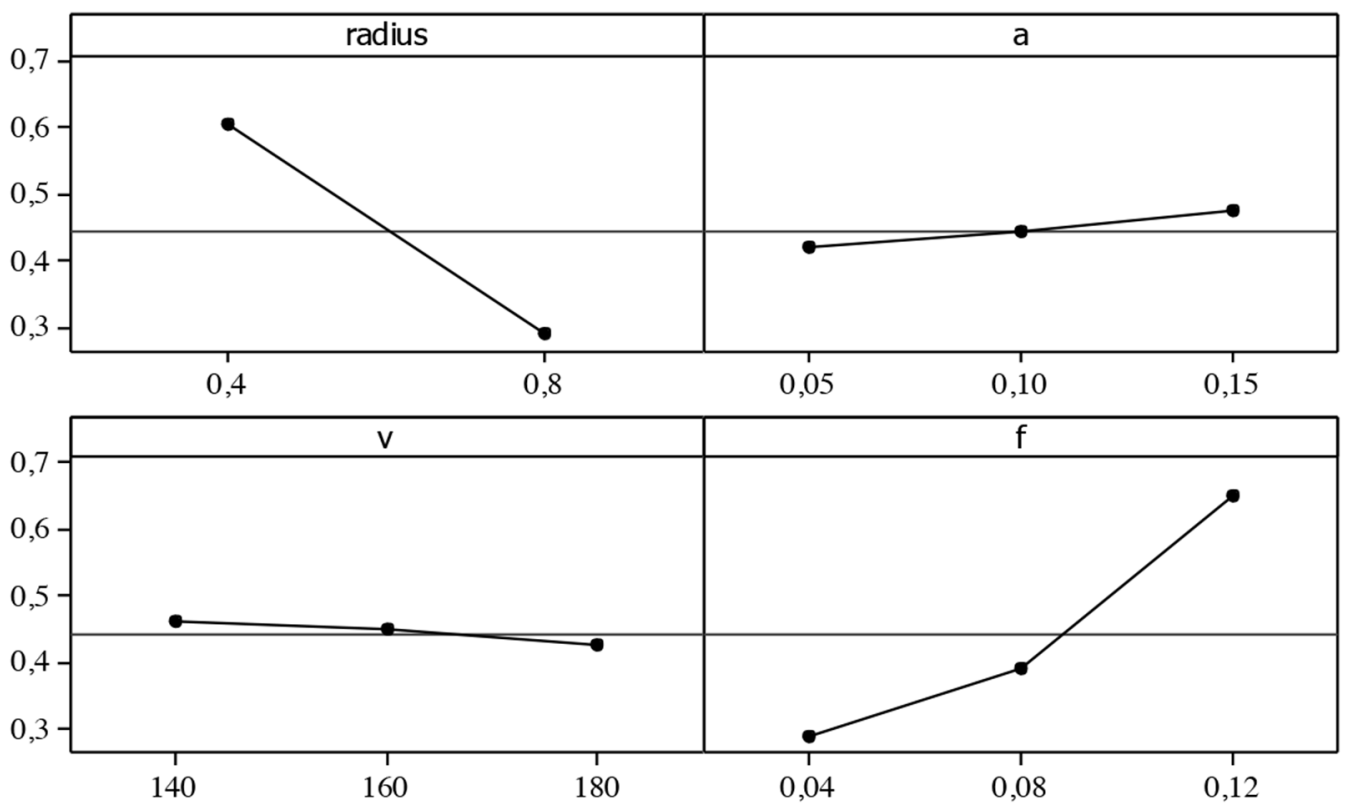

Fig. 7. Mean changes in selected parameters on surface roughness. 

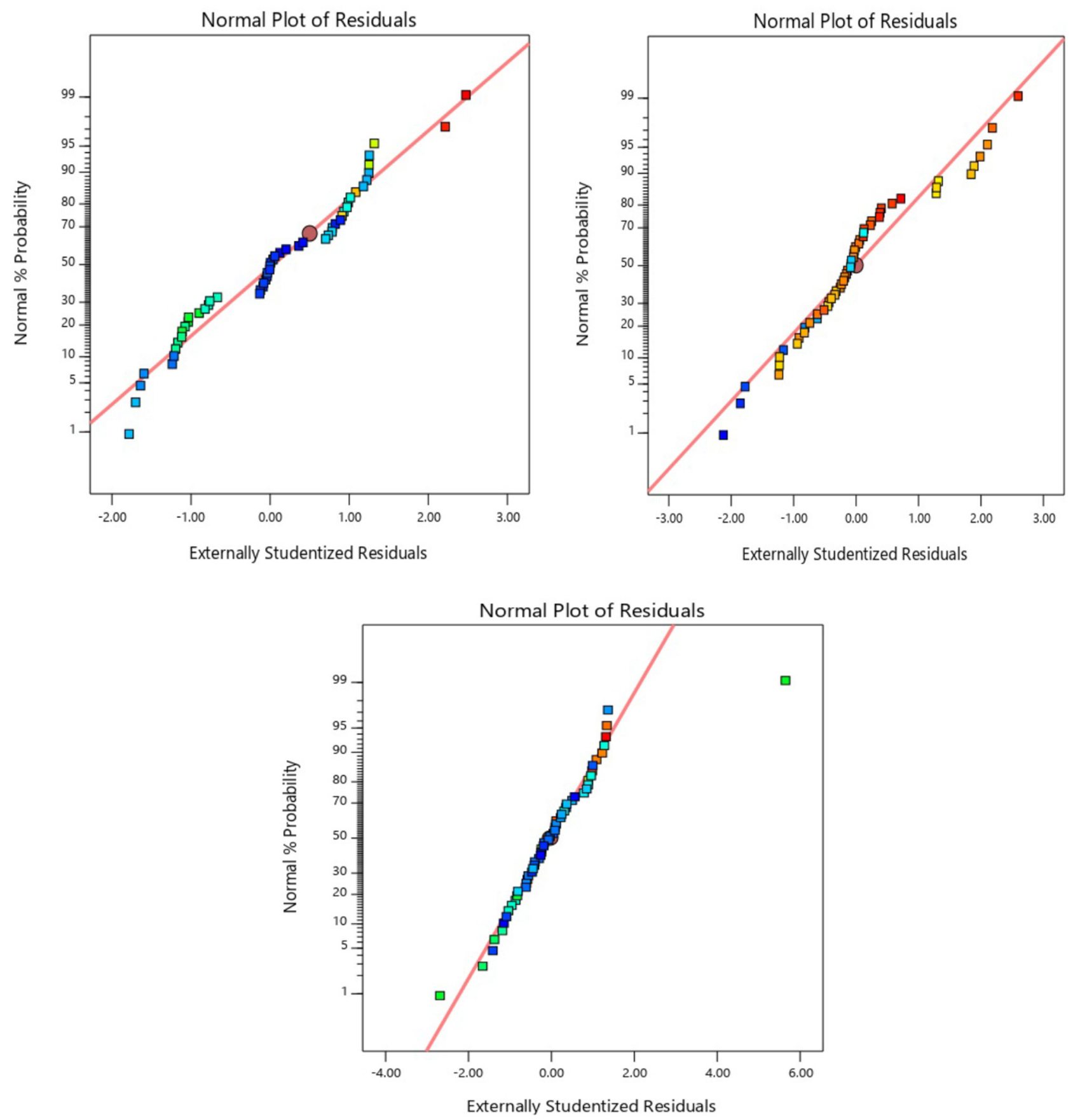

Fig. 8. Normality graphs of response variables.

Table 7. Multi response optimization.

\begin{tabular}{lllllllll}
\hline $\begin{array}{l}\text { Solution } \\
\text { No }\end{array}$ & $\begin{array}{l}\text { Cutting } \\
\text { Speed }\end{array}$ & $\begin{array}{l}\text { Feed } \\
\text { Rate }\end{array}$ & $\begin{array}{l}\text { Depth } \\
\text { of cut }\end{array}$ & Radius & $\begin{array}{l}\text { Power } \\
\text { Consumption }\end{array}$ & $\begin{array}{l}\text { Sound } \\
\text { Level }\end{array}$ & $\begin{array}{l}\text { Surface } \\
\text { Roughness }\end{array}$ & Desirability \\
\hline 1 & 180 & 0.05 & 0.12 & 0.8 & 26874.6 & 69.81 & 0.269 & 0.996 \\
2 & 180 & 0.05 & 0.12 & 0.798 & 26910 & 69.83 & 0.272 & 0.994 \\
3 & 180 & 0.05 & 0.12 & 0.799 & 27505.4 & 69.806 & 0.268 & 0.994 \\
4 & 180 & 0.05 & 0.12 & 0.799 & 27540.8 & 69.823 & 0.271 & 0.993 \\
5 & 178 & 0.05 & 0.12 & 0.799 & 28096.5 & 69.817 & 0.272 & 0.993 \\
\hline
\end{tabular}



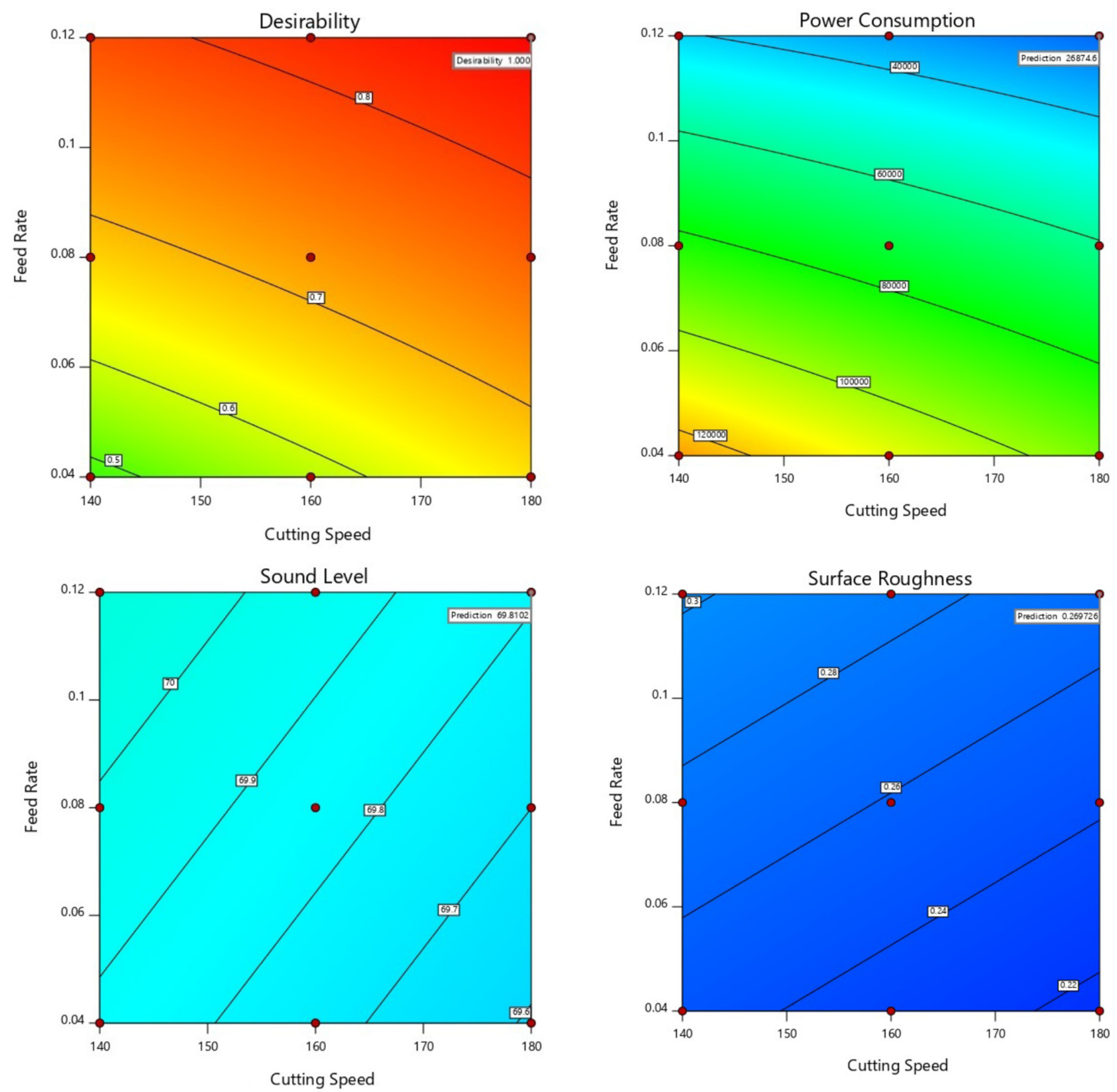

Fig. 9. Desirability graphs of response variables.

After multi-objective optimization, the values of machining parameters obtained are: cutting speed of $180.00(\mathrm{~m} / \mathrm{min})$, the feed rate of $0.05(\mathrm{~mm})$, depth of cut of $0.12(\mathrm{~mm})$ and radius of $0.80(\mathrm{~mm})$. After these values of machining parameters are put in equation (7), the corresponding values of power consumption, sound level and surface roughness are 27349 Watt, $69.8217 \mathrm{~dB}$ and $0.307216 \mu \mathrm{m}$, respectively.

The $\%$ reduction in power consumption

$$
=\frac{27349-26874.6}{27349} \times 100=1.7 \%
$$

The $\%$ reduction in sound level

$$
=\frac{69.8217-69.81}{69.8217} \times 100=0.016 \%
$$

The $\%$ reduction in surface roughness

$$
=\frac{0.307-0.269}{0.307} \times 100=12.3 \%
$$

\section{Conclusion}

Surface roughness and power consumption has paramount importance in hard turning in the manufacturing industry. In this experimental study, feed rate, cutting speed, depth of cut and tool nose radius parameters were selected to 
investigate the surface roughness, power consumption and sound level. As a result, the most effective parameters in power consumption are depth of cut, feed rate and cutting speed. Effective parameters in surface quality are found as feed rate and tool radius. Depth of cut and radius were found to be effective on the sound level. After multiobjective optimization, the values of machining parameters obtained are: cutting speed of $180.00(\mathrm{~m} / \mathrm{min})$, the feed rate of $0.05(\mathrm{~mm})$, depth of cut of $0.12(\mathrm{~mm})$ and radius of $0.80(\mathrm{~mm})$. According to the model and optimization results, a decrease of $1.7 \%$ in energy consumption and a decrease of $12.3 \%$ in surface roughness was achieved.

It is clear that using appropriate cutting tools in hard turning is of great importance to achieve surface quality as close to the grinding process. Feed rate was found to be significant on the surface roughness. Low feed rates are preferred for a low surface roughness value. Although the instantaneous current value increases with increasing the cutting parameters, the total power consumption is reduced. The most effective parameter on the total power consumption is the processing time. Increasing the cutting parameters is effective in shortening the machining time.

Cutting speed and depth of cut are increased slightly to reduce machining time, while the feed rate is reduced to improve surface quality.

The reason for the low current value and sound intensity range is due to the low depth of cut. However, there is a strong relationship between the current value and the cutting parameters. The reason why this change in sound volume occurs regularly is the sound generated by the hitting of the chips. Therefore, the volume is not a clear enough indication in the finish turning process.

\section{References}

[1] A. Salimi Asl, A. Erdem, M. Rafighi, Applying a multi sensor system to predict and simulate the tool wear using of artificial neural networks, Scientia Iranica. 24, 2864-2874 (2017)

[2] I. Ciftci, Machining of austenitic stainless steels using CVD multi-layer coated cemented carbide tools, Tribol. Int. 39, 565-569 (2006)

[3] S. Karabulut, A. Sahinoglu, Effect of the cutting parameters on surface roughness, power consumption and machine noise in machining of R260 steel, J. Polytech. Politek. 21, 237-244 (2018)

[4] M. Özdemir, M.T. Kaya, H.K. Akyildiz, Analysis of surface roughness and cutting forces in hard turning of $42 \mathrm{CrMo} 4$ steel using Taguchi and RSM method, Mechanics 26, 231-241 (2020)

[5] A. Şahinoğlu, M. Rafighi, Optimization of cutting parameters with respect to roughness for machining of hardened AISI 1040 steel, Mater. Test. 62, 85-95 (2020)

[6] A. Şahinoğlu, Ş. Karabulut, A. Güllü, Study on spindle vibration and surface finish in turning of $\mathrm{Al} 7075$, Solid State Phenom. 261, 321-327 (2017)
[7] S.A. Bagaber, A.R. Yusoff, Multi-objective optimization of cutting parameters to minimize power consumption in dry turning of stainless steel 316, J. Clean. Prod. 157, 30-46 (2017)

[8] R.K. Bhushan, Optimization of cutting parameters for minimizing power consumption and maximizing tool life during machining of $\mathrm{Al}$ alloy $\mathrm{SiC}$ particle composites, J. Clean. Prod. 39, 242-254 (2013)

[9] S.K. Nayak, J.K. Patro, S. Dewangan, S. Gangopadhyay, Multi-objective optimization of machining parameters during dry turning of AISI 304 austenitic stainless steel using grey relational analysis, Proc. Mater. Sci. 6, 701-708 (2014)

[10] A. Şahinoğlu, M. Rafighi, Investigation of vibration, sound intensity, machine current and surface roughness values of AISI 4140 during machining on the Lathe, Arab. J. Sci. Eng. 45, 765-778 (2020)

[11] L. Zhou, J. Li, F. Li, Q. Meng, J. Li, X. Xu, Energy consumption model and energy efficiency of machine tools: a comprehensive literature review, J. Clean. Prod. 112, 3721-3734 (2016)

[12] A. Junaidh, G. Yuvaraj, J. Peter, V. Bhuvaneshwari, K. Karthik, Influence of process parameters on the machining characteristics of austensite stainless steel (AISI 304), Mater. Today 5, 13321-13333 (2018)

[13] A. Kulkarni, V. Sargade, C. More, Machinability investigation of AISI 304 austenitic stainless steels using multilayer AlTiN/TiAlN coated carbide inserts, Proc. Manuf. 20, 548-553 (2018)

[14] P.S. Bilga, S. Singh, R. Kumar, Optimization of energy consumption response parameters for turning operation using Taguchi method, J. Clean. Prod. 137, 1406-1417 (2016)

[15] A. Şahinoğlu, A. Güllü, M.A. Dönertas, GGG50 Malzemenin Torna Tezgâhında Farklı Kesme Parametrelerinde İslenmesinde Titresim, Ses Siddetinin ve Yüzey Pürüzlülügünün İncelenmesi, Sinop Üniv. Fen Bilim. Derg. 2, 67-79 (2017)

[16] W. Grzesik, B. Denkena, K. Zak, T. Grove, B. Bergmann, Energy consumption characterization in precision hard machining using CBN cutting tools, Int. J. Adv. Manuf. Technol. 85, 2839-2845 (2016)

[17] G. Kant, K.S. Sangwan, Prediction and optimization of machining parameters for minimizing power consumption and surface roughness in machining, J. Clean. Prod. 83, 151-164 (2014)

[18] P. Patole, V. Kulkarni, Optimization of process parameters based on surface roughness and cutting force in MQL turning of AISI 4340 using nano fluid, Mater. Today 5, 104-112 (2018)

[19] A. Ghani, I. Choudhury, Study of tool life, surface roughness and vibration in machining nodular cast iron with ceramic tool, J. Mater. Process. Technol. 127, 17-22 (2002)

[20] S.R. Das, D. Dhupal, A. Kumar, Experimental investigation into machinability of hardened AISI 4140 steel using TiN coated ceramic tool, Measurement 62, 108-126 (2015)

[21] A. Salımıasl, M. Rafıghı, Titresim ve Kesme Kuvveti Esaslı Takım Asınmasının Bulanık Mantıkla İzlenmesi ve Tahmini, Politek. Derg. 20, 111-120 (2017)

[22] A. Salimiasl, M. Rafighi, Talas Kaldırma İslemlerinde Takım Durumunun İzlemesi İçin Son Gelismelerin İncelenmesi, Düzce Üniv. Bilim Teknol. Derg. 5, 314-337 (2017)

Cite this article as: A. Şahinoğlu, E. Ulas, An investigation of cutting parameters effect on sound level, surface roughness, and power consumption during machining of hardened AISI 4140, Mechanics \& Industry 21, 523 (2020) 